\title{
Southern Hemisphere Breeding Stock D humpback whale population estimates from North West Cape, Western Australia
}

\author{
Chandra Salgado Kent*, Curt Jenner ${ }^{+}$, Micheline Jenner ${ }^{+}$, Philippe Bouchet* and Eric Rexstad \\ Contacte-mail: c.salgado@cmst.curtin.edu.au
}

\begin{abstract}
Estimates of the abundance of Breeding Stock D humpback whales (Megaptera novaeangliae) are key to the conservation and management of what is thought to be one of the largest populations of the species. Five years $(2000,2001,2006,2007$ and 2008) of aerial surveys carried out over an eight-year period at North West Cape (Western Australia) using line transect methodology allowed trends in whale numbers to be investigated, and provided a base for comparison with estimates made approximately $400 \mathrm{~km}$ south at Shark Bay (Western Australia). A total of 3,127 whale detections were made during 74 surveys of the $7,043 \mathrm{~km}^{2}$ study area west of NWC. Pod abundance for each flight was computed using a HorvitzThompson like estimator and converted to an absolute measure of abundance after corrections were made for estimated mean cluster size, unsurveyed time, swimming speed and animal availability. Resulting estimates from the migration model of best fit with the most credible assumptions were $7,276(\mathrm{CI}=4,993-10,167)$ for $2000,12,280(\mathrm{CI}=6,830-49,434)$ for $2001,18,692(\mathrm{CI}=12,980-24,477)$ for $2006,20,044(\mathrm{CI}=13,815-31,646)$ for 2007, and 26,100 (CI $=20,152-33,272)$ for 2008. Based on these data, the trend model with the greatest $r^{2}$ was exponential with an annual increase rate of $13 \%(\mathrm{CI}=5.6 \%-18.1 \%)$. While this value is above the species' estimated maximum plausible growth rate of $11.8 \%$, it is reasonably close to previous reports of between 10-12\%. The coefficient of variation, however, was too large for a reliable trend estimate. Perception bias was also not accounted for in these calculations. Based on a crude appraisal which yielded an estimated $p(0)$ of 0.783 (from independent observer effort, $\mathrm{CV}=0.973$ ), the 2008 humpback population size may be as large as 33,300. In conclusion, the work here provides evidence of an increasing Breeding Stock D population, but further surveys are necessary to confirm whether the population is indeed increasing at its maximum rate.
\end{abstract}

KEYWORDS: ABUNDANCE ESTIMATE; SURVEY-AERIAL; MIGRATION; MODELLING; TRENDS

\section{INTRODUCTION}

The population of humpback whales (Megaptera novaeangliae) known as Southern Hemisphere Breeding Stock D (IWC, 1998) migrates annually from Antarctica to the Kimberley region (northwestern Australia) along the Western Australian (WA) coastline (Jenner et al., 2001). This population has one of the longest records of study and management in the Southern Hemisphere, due to its long history of exploitation from the whaling industry (Bannister, 1964; 1991; 1994; Bannister et al., 1991; Chittleborough, 1953; 1965). Assessment of its size, however, has been a more recent undertaking and thus far, three 'best estimates' of 11,500 for surveys in $1999,12,800$ for surveys in 2005, and 33,850 for surveys in 2008 have been produced at Shark Bay, WA (Bannister and Hedley, 2001; Hedley et al., 2011; Paxton et al., 2011). Whilst these previous works provide a framework from which to begin trend estimation, the wide confidence intervals (typical of cetacean population estimates) and limited data points (three years) point towards the need for supplementary monitoring. Consequently, the general aim of this study was to: (1) supplement existing knowledge with data gathered from the same population but at a location approximately $400 \mathrm{~km}$ north of Shark Bay (at North West Cape) over five years; and (2) define a possible trend in the abundance of Breeding Stock D humpback whales based on combined North West Cape (NWC) and Shark Bay survey results. The work presented here provides significant information on the current status of Breeding
Stock D - information essential for the effective long-term conservation and management of the population.

\section{METHODOLOGY}

Steps taken to fulfil the objectives of this study were: (1) for each survey, daily abundance was estimated; (2) a migration model was fitted for each year; (3) annual population abundance using the migration models were estimated; and (4) the population abundance trend between 2001 and 2008 was estimated.

\section{Daily survey abundance estimates \\ Survey area and design}

Aerial surveys were conducted between June and November west of NWC during 2000, 2001, 2006, 2007, and 2008, in an area where humpback whales travel within close proximity to the shore (Chittleborough, 1953; Jenner et al., 2001; Fig. 1). A total of eight tracks $10 \mathrm{~km}$ apart and taking about four hours to complete were surveyed consistently every year in a direction against that of the general whale migration during the northern migration (from transect 1 to 8 ; Fig. 1) and in the direction of the migration during the southern migration. The travel speed of the aircraft $\left(\sim 20 \mathrm{~km} \mathrm{hr}^{-1}\right)$ in the direction of southerly migrating whales was much greater than the travel speed of the whales $\left(\sim 4 \mathrm{~km} \mathrm{hr}^{-1}\right)$, hence sampling the same animals on adjacent transects was highly improbable. The eight tracks resulted in a total region surveyed of $7,043 \mathrm{~km}^{2}$. The timing of the first and last flights of each field

\footnotetext{
* Centre for Marine Science and Technology (CMST), Curtin University, GPO Box U 1987 Perth 6845, WA, USA.

${ }^{+}$Centre for Whale Research, WA (Inc.), P.O. Box 1622, Fremantle 6959, WA, USA.

* Scottish Oceans Institute, University of St. Andrews, East Sands, St. Andrews, Fife, KY16 8LZ, UK.

Centre for Research into Environmental and Ecological Management, Buchanan Gardens, University of St. Andrews, Fife, KY16 $9 L Z$, UK.
} 


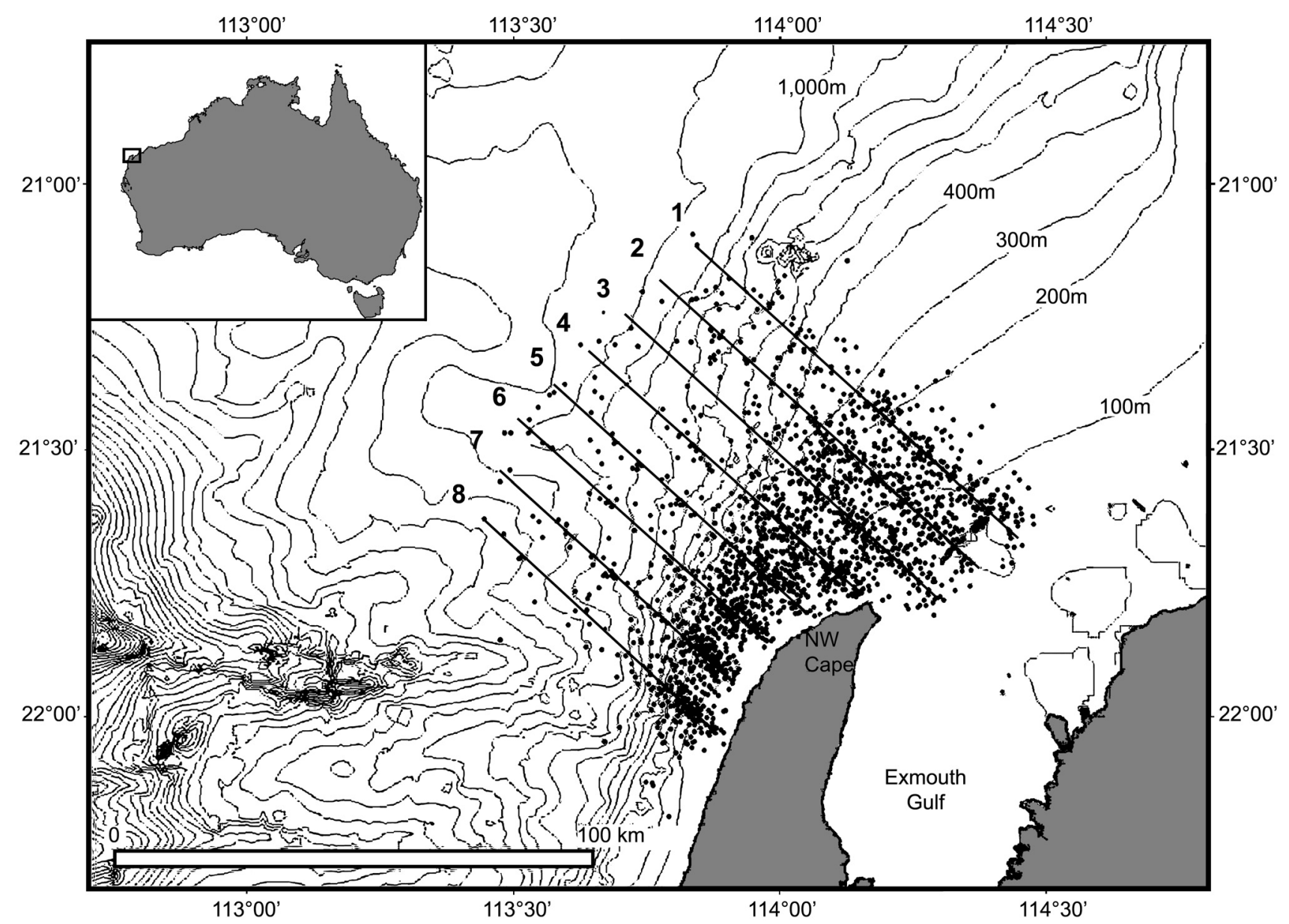

Fig. 1. Aerial survey tracks conducted during 2000, 2001, 2006, 2007, and 2008 west of North West Cape, Western Australia, with positions of all pod detections overlayed on the map (black circles).

season varied among years, but most were spaced 5 to 10 days apart (Table 1). Surveys were designed to cover the whales' northern migration (June to August) and southern migration (August to November), with the exception of the survey in 2008 which only covered the northern migration. During the five years, a total of 74 flights were carried out: 17 in 2000, 17 in 2001, 14 in 2006, 13 in 2007, and 13 in 2008.
Data collection and analysis

Aerial surveys were flown at an altitude of $305 \mathrm{~m}(1,000 \mathrm{ft})$ and a speed of $222 \mathrm{~km} \mathrm{hr}^{-1}$ (120 knots) using a Cessna 337, or a Partenavia P68B aircraft (twin engine, overhead wing aircraft) fitted with bubble windows (to maximise viewing under the plane) or with standard windows (depending upon aircraft availability). The type of platform used remained consistent

Table 1

Number of humpback whale pod detections for 2000, 2001, 2006, 2007 and 2008 North West Cape aerial surveys

\begin{tabular}{|c|c|c|c|c|c|c|c|c|c|}
\hline \multicolumn{2}{|c|}{2000} & \multicolumn{2}{|c|}{2001} & \multicolumn{2}{|c|}{2006} & \multicolumn{2}{|c|}{2007} & \multicolumn{2}{|c|}{2008} \\
\hline Date & $\begin{array}{l}\text { Number } \\
\text { detected }\end{array}$ & Date & $\begin{array}{l}\text { Number } \\
\text { detected }\end{array}$ & Date & $\begin{array}{l}\text { Number } \\
\text { detected }\end{array}$ & Date & $\begin{array}{l}\text { Number } \\
\text { detected }\end{array}$ & Date & $\begin{array}{l}\text { Number } \\
\text { detected }\end{array}$ \\
\hline 11 Jun. & 1 & 10 Jun. & 2 & 13 Jun. & 1 & 24 Jun. & 4 & 24 Jun. & 8 \\
\hline 12 Jun. & 1 & 11 Jun. & 4 & 19 Jun. & 5 & 01 Jul. & 5 & 27 Jun. & 23 \\
\hline 19 Jun. & 10 & 17 Jun. & 3 & 26 Jun. & 16 & 08 Jul. & 38 & 01 Jul. & 27 \\
\hline 20 Jun. & 5 & 30 Jun. & 8 & 08 Jul. & 23 & 14 Jul. & 44 & 05 Jul. & 23 \\
\hline 12 Jul. & 30 & $20 \mathrm{Jul}$. & 28 & 29 Jul. & 40 & 05 Aug. & 59 & 15 Jul. & 98 \\
\hline 22 Jul. & 20 & 29 Jul. & 15 & 06 Aug. & 77 & 19 Aug. & 44 & 28 Jul. & 88 \\
\hline 23 Jul. & 15 & 12 Aug. & 50 & 20 Aug. & 72 & 31 Aug. & 75 & 01 Aug. & 27 \\
\hline 04 Aug. & 31 & 24 Aug. & 121 & 25 Aug. & 41 & 09 Sep. & 37 & 08 Aug. & 63 \\
\hline 13 Aug. & 60 & 11 Sep. & 27 & 09 Sep. & 19 & 23 Sep. & 13 & 09 Aug. & 72 \\
\hline 25 Aug. & 92 & 22 Sep. & 27 & 20 Sep. & 6 & 08 Oct. & 11 & 16 Aug. & 71 \\
\hline 17 Sep. & 30 & 08 Oct. & 23 & 29 Sep. & 12 & 14 Oct. & 7 & 19 Aug. & 54 \\
\hline 24 Sep. & 9 & 21 Oct. & 3 & 07 Oct. & 4 & 25 Oct. & 3 & 27 Aug. & 68 \\
\hline 29 Oct. & 3 & 10 Nov. & 4 & & & & & & \\
\hline 12 Nov. & 1 & 30 Oct. & 1 & & & & & & \\
\hline 26 Nov. & 3 & 10 Nov. & 5 & & & & & & \\
\hline
\end{tabular}


throughout any single season, except in 2000, where the first eleven flights were completed with a Partenavia fitted with bubble windows, and the last six with a Partenavia with standard windows. The plane followed box-end line transects (Fig. 1) which were surveyed in passing mode (e.g. no deviation from the flight path). Survey tracks were $10 \mathrm{~km}$ apart and were designed to be perpendicular to bathymetric contours and to the known humpback whale migratory path.

Personnel for all surveys before 2006 included two pilots, two observers and a data recorder. The observers and data recorder were linked via a separate intercom system from the pilots, and the data were logged with a time code to a digital tape recorder. Observers measured vertical and horizontal angles from the plane to each sighted pod (using Suunto PM5/360PC clinometers and a compass board), while the pilots recorded the angle of drift of the aircraft from the flight path (for diagram of angles see Lerczak and Hobbs, 1998 ). All relevant animal data (i.e. group size, migratory heading) were entered into a palm-top computer by the data typist. GPS coordinates and altitudes were logged in a laptop computer for every second of the flight, and subsequently used to link the palm-top computer with the digital tape recorder. Each device was calibrated to $\pm 1 \mathrm{sec}$ accuracy at the beginning of each flight. Whales' travel direction were categorised as 'north', 'south', or 'milling' for each observed pod. Groups reported as 'milling' were generally surface lying at the time of sighting with no obvious signs of swimming activity or were swimming slowly in different directions at each surfacing. Observers who were unable to determine the nature of the whales' movements and/or surface behaviour classified their direction of travel as 'undetermined'.

From 2006 onwards, a time-coded Mini-Disk recorder (Sony Mini Disk Recorder NH900), which was synchronised to the GPS prior to takeoff, was used (instead of a data typist) to record animal data and the time that waypoints were marked on the GPS for each detection.

True angles from the aircraft to the animals were later calculated with the following formula: $A W=A C+M H A \pm$ $D A$, where $A W$ is the angle to the whale, $A C$ the aircraft course, $M H A$ the measured horizontal angle and $D A$ the angle of drift of the aircraft, which was either subtracted or added depending upon the side of the aircraft the animal was sighted on (as defined and described in Lerczak and Hobbs, 1998). Radial distances were calculated using equations detailed in Lerczak and Hobbs (1998). In 2008, an independent observer (or 'double blind') configuration was used every other survey, and required in a total of 5-6 personnel (including four observers, two on each side of the aircraft).

\section{Detection function and abundance estimation}

All analyses described here forward were run using R v2.9.2 (The R Foundation for Statistical Computing 2006) and DISTANCE 6.0 release 2 (Thomas et al., 2010).

Conventional Distance Sampling techniques (Buckland et al., 2001; 2004) were used to estimate the abundance of humpback whales migrating past NWC. First, estimates of pod abundance $\left(\hat{N}_{\text {pods }}\right)$ were computed using a HorvitzThompson like estimator:

$$
\hat{N}_{p o d s}=\frac{n}{p(x)} \frac{A}{2 L w}
$$

where $n$ is the number of detections made during any one flight, $A$ is size of study region, $p(x)$ is the average probability of detection (estimated for each survey; fit shown for pooled data in Fig. 2), $L$ is the total survey effort, and $w$ is the perpendicular right-truncation distance.

A right-truncation distance of $w=13 \mathrm{~km}$ was chosen since smaller values dramatically reduced the number of available observations for surveys at the beginning and at the end of the migration seasons, thereby compromising the estimation
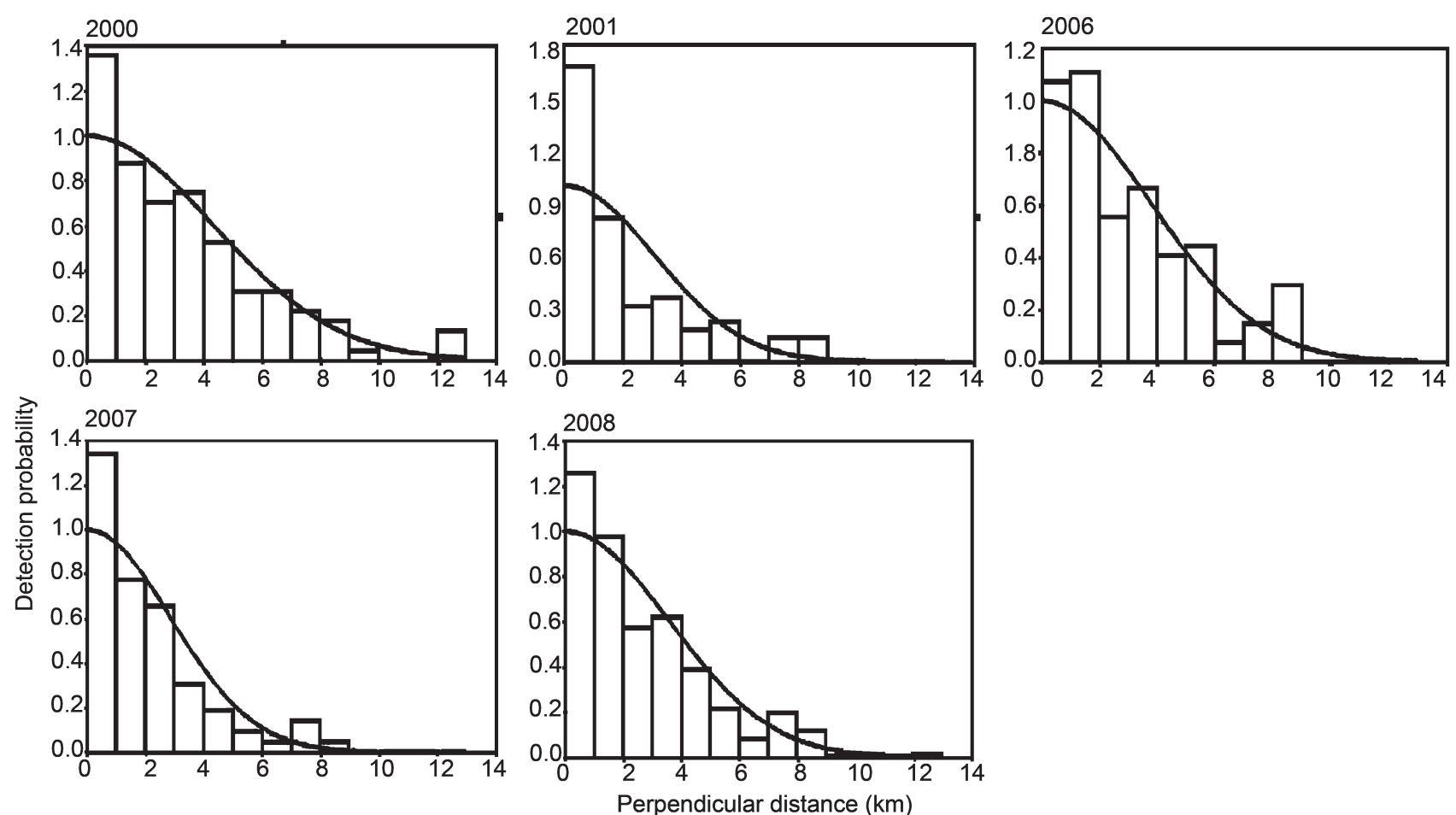

Fig. 2. Detection probability (pooled by year) as function of perpendicular distance from flight line for the northern migration using Approach no. 2 during 2000, 2001, 2006, 2007 and 2008. 
of daily abundance and lowering the number of surveys which could be incorporated into the final migration model. Approximately one to two surveys at the beginning and at the end of the migration would have had to have been removed from the annual migration models if a righttruncation distance of $w=10 \mathrm{~km}$ had been used. In a model where the greatest source of variation is from the migration model itself, it is important to elevate the number of surveys informing the migration model as much as possible. Violating the assumption of independence between transects (by having a right truncation distance larger than the intertransect distance) was considered to be a less significant problem than the uncertainty associated with inferences made from a limited number of data points. By having the covered area of transects overlap, there is a possibility that some animals may be detected from $>1$ transect. This has no effect upon the point estimate which is calculated as a function of encounter rate, but the estimated variance of the density estimate may be too small. The inclusion of the small number of detections at large distances, however, allowed for a detection function to be fitted to surveys where only a handful of whales were detected (surveys with too few detections were not included since corresponding detection functions were either unreliable or could not be fitted).

Observers' viewing ranges were restricted between $10^{\circ}$ and $140-160^{\circ}$ of the nose of the airplane, and visual obstruction by the fuselage and wheels only permitted maximum declination angles of $84^{\circ}$ when using bubble, or $38^{\circ}$ when using flat windows (with $0^{\circ}$ at the horizon). These conditions gave blind strips of $31 \mathrm{~m}(0.02$ n.miles $)$ or $390 \mathrm{~m}$ ( 0.21 n.miles $)$ either side of the path for the elevated height considered here. The different results due to visibilities offered by both flat and bubble windows were tested and deemed equivalent (Bouchet, 2009), and availability computations were made by choosing the angular margins of the view-field as the minimum and maximum bearings recorded in each year. In this way the time windows for observing pods were estimated for each year. Data were left-truncated at $0.75 \mathrm{~km}$ as it was assumed that complete detection ought to have been achieved at this distance (Bouchet, 2009).

The probability of detecting a whale $p(x)$ can be regarded as the outcome of two contiguous events; namely (1) the animal is or becomes available to be seen and (2) it is spotted by an observer. This can be described mathematically by:

$$
\int_{0}^{w} p(\operatorname{seen} \mid a, x) p(a \mid x) \frac{1}{w} d x
$$

where $p(\operatorname{seen} \mid a, x)$ is the probability of being seen given that the pod is available $(a)$ for detection (at the surface) and $p(a=1 \mid x)$ is the probability of the pod being available for detection. $p(\operatorname{seen} \mid a, x)$ was determined based on the fitting of a constrained half-normal key function inside Distance 6.0 (this was the best fitting function of those available within Distance 6.0):

$$
p(\operatorname{seen} \mid a, x)=e^{\frac{x^{2}}{2 \sigma^{2}}}
$$

The integration of covariates associated with each observation such as glare, sea state, cloud cover, and observer into the model was explored. While cloud cover was not correlated with detections, glare, sea state, and to a lesser extent observer appeared to have some effect, although this effect did not change the AIC scores significantly. Because the correlations were inconsistent in their nature and the AICs did not improve significantly, integrating these covariates into the model was deemed inappropriate.

To estimate $p(a=1 \mid x)$ the following equation developed by Laake et al. (1997) was applied:

$$
\hat{p}(a \mid \mathrm{x})=\frac{E[s]}{E[s]+E[d]}+\frac{E[d]\left(1-e^{\frac{-t}{E[d]}}\right.}{E[s]+E[d]}
$$

where $E[s]$ is the expected time a whale spends at the surface, $E[d]$ is its expected dive duration, and $t$ is the time the animal is within detectable range (given the physical constraints of the aircraft). The time that a humpback stays in view is a function of the viewing angle forward and aft of the perpendicular line to the aircraft's centreline (Fig. 3) and of the aircraft's velocity, and was computed by:

$$
t=\frac{d_{1}+d_{2}}{v}
$$

where $v$ represents the plane's cruising speed (120 n.miles $\mathrm{hr}^{-1}$ ), and $d_{1}+d_{2}$ is the distance covered by the animal within the detection range of the observer ('time window'). Distances varied since they depended upon the position of the pod relative to the aircraft, and were calculated trigonometrically (Fig. 3). The expected surfacing time and expected dive duration $(E[s]$ and $E[d]$, respectively) were estimated by obtaining the average of randomly sampled dive-surface pairs (with replacement) from observations made of 44 pods during 22 dedicated boat-based focal follows conducted within the same area as the aerial surveys, between 22 July and 18 September 2002. These vessel-based surveys consisted of closing mode approaches conducted from a $6 \mathrm{~m}$ centre console, inflatable Zodiac, with a crew comprising of a driver, a notetaker and a marksman/photographer. The surveys were carried

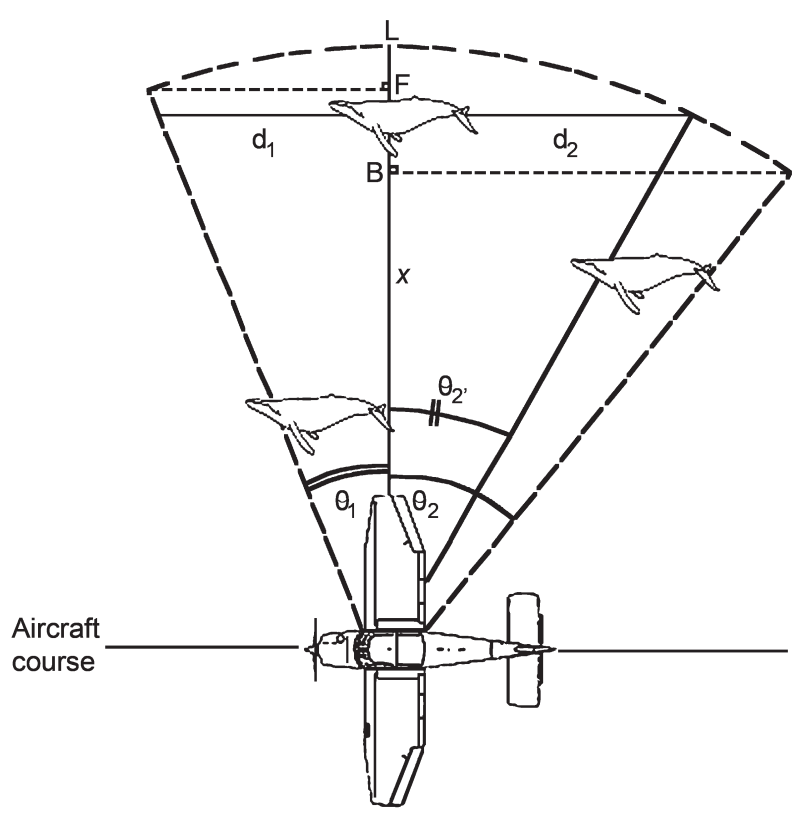

Fig. 3. Diagram of the view-field and detection range available to observers onboard an aircraft, where $L=$ outer limit of the viewing range, $\theta_{l}=$ fore angle of view, $\theta_{2}=$ aft angle of view, $\theta_{2}{ }^{\prime}=$ aft angle to the whale when it comes into view, $x=$ sighting distance (relative to the aerial track), and $d_{1}+d_{2}=$ time window 
out haphazardly within the study region and were aimed at gathering behavioural information on movements and travelling speeds, and collecting biopsy samples and photoidentification images. The latter two data types were collected as part of an independent study and are not discussed here. Only those observations made prior to biopsy sampling have been included in the analyses presented here, in an effort to only rely on information reflecting conditions of minimum observer disturbance. Dive times were measured as the time between surfacing events (of the last individual of the pod to dive and the first individual of the pod to surface), while surfacing intervals were defined as the time from the first individual of the pod to blow (after a dive) to the last individual of the pod to blow (before the following dive).

Estimates of pod abundance $\left(\hat{N}_{\text {pods }}\right)$ for each flight were converted to estimates of individual abundance $\left(\hat{N}_{\text {individuals }}\right)$ by multiplying the former by the estimated mean cluster size. This was obtained by regressing the log of the observed cluster size against the estimated detection probability for each survey, thereby accounting for the potentially greater visibility of larger pods with increasing distance from the track line to produce an unbiased estimate of the average size of pods in the population.

The daily number of individual animals migrating past NWC was then estimated by multiplying the above individual abundance by the mean whale speed $(\mathrm{km} / \mathrm{hr})$ and the number of hours in a day (24), and dividing it by the total latitudinal length of the survey area in $\mathrm{km}(80 \mathrm{~km})$. The method applied is roughly consistent with that described in Buckland et al. (2004) This approach assumes that there is a constant rate of migration through the area over the period of a day, and that the estimate derived from each survey is an 'instantaneous' abundance estimate. Pod speed was obtained from the 2002 boat surveys by marking GPS waypoints and recording the time taken and distance covered from the beginning of a surfacing event to the beginning of the subsequent one. Average whale speed was found to be $5.65 \mathrm{~km} \mathrm{hr}^{-1}(\mathrm{SE}=0.33)$ for northerly migrating whales, and $4.07 \mathrm{~km} \mathrm{hr}^{-1}(\mathrm{SE}=0.24)$ for southerly migrating whales.

\section{Perception bias}

While estimates of availability bias were achieved for all surveys, estimates of perception bias were only possible for surveys undertaken in 2008 (since this was the only year when an independent observer setup was in place). As a consequence, these are presented separately to the overall population size estimates (described below), so that trend estimation is based on results derived from comparable methods.

To evaluate the extent of perception bias, data were lefttruncated at $0.75 \mathrm{~km}$ to remain consistent with previous analyses and then imported into Distance 6.0 to be analysed using the available Mark-Recapture Distance Sampling (MRDS) tools. A set of 75 contending mark-recapture models was examined with various combinations of covariates which affect detectability (i.e. perpendicular distance, sea state, glare intensity, minimum and maximum glare angles, angle of drift from the plane, wind speed, wind direction, survey date, cluster size and observer). Cluster size, observer, glare, Beaufort sea state, and survey date were treated as factor variables. The models were tested under the assumption of full independence (FI) only (Buckland et al., 2004), and the model of best fit was selected based on its Akaike Information Criterion (AIC) score.

\section{Annual population abundance estimates using the migration models}

To extrapolate estimates to days when surveys could not be completed, a smooth line was fitted to abundance estimates for the days in which surveys were completed during each year, resulting in an estimated number of whales migrating past NWC each day of the year. The smooth line represents the migration model. Several migration models consisting of either one (unimodal) or a mixture of two or three normals, whose parameters $\mu$ (mean) and $\sigma$ (variance) were found by Maximum Likelihood Estimation (MLE; Borchers et al., 2002), were tested for best fit (using Akaike Information Criterion values). Integrating the area under the entire density function then provided an estimate of the total number of whales filing through the region during their migration. Because whales migrate past NWC twice (once on their way north to their breeding grounds, and a second time south during their return to polar feeding grounds), assessments of the population size must be based on one of these phases. Three approaches were taken to tackle this issue, and their respective results compared.

(1) Northerly and southerly travelling whales were separated according to their recorded direction of travel. Here, northerly travelling whales were assumed to be migrating north, and southerly travelling whales were assumed to be migrating south. Those entered as 'milling' or 'unknown' were randomly allocated 'north' or 'south', proportionally to the observed ratio of northerly to southerly travelling whales. This was done for blocks of time equivalent to the maximum time interval between surveys in any one year. Depending upon the year, the blocks ranged from 16 to 20 days.

(2) Northerly and southerly travelling whales were separated as above (1), but in addition survey dates which fell outside the expected end of the northern and beginning of the southern migrations were excluded. The expected end of the northern migration was deemed to be the time at which the proportion of northbound whales fell to less than 0.2 and the proportion southbound rose to above 0.8 , corresponding to the 15-20 August. Similarly, the expected beginning of the southern migration was regarded as the time at which the percentage of observed southbound whales exceeded 0.2 , which coincided with 10-15 August. The rationale behind this strategy is that humpback whales are known to spend a considerably greater amount of time milling during their southbound migration, leading to an elevated risk of recording a southbound whale as migrating north (when in fact the animals are only temporarily moving north during their southbound migration). By truncating the data early, an attempt was made at excluding data at the tails of the migration curve which were prone to errors in recording the migration direction (of milling southbound animals), and instead to allow the migration models to estimate the expected tails (in the absence of migration direction errors). 
(3) Northerly and southerly travelling whales were incorporated into one single model, and the resulting estimate was halved.

In all circumstances, the tails of the migration curves were required to be 'pinned down' so as to ensure better performance. This was done on a case-to-case basis by adding zero counts at the onset and end of the migration pulses.

To quantify the uncertainty inherent to the final abundance estimate, each working parameter (namely encounter rate, probability of detection (adjusted for availability), travelling speed, pod size, and migration model fit was bootstrapped (with replacement, $\mathrm{B}=1,000$ pseudo samples). The distribution of replicates allowed coefficients of variation (CV) to be produced and $95 \%$ confidence intervals to be calculated using the percentile method. Individual coefficients were then combined into an overall $\mathrm{CV}$ based on the Delta method (Buckland et al., 2004).

$$
C V_{\hat{N}_{\text {pop }}}=\sqrt{\left(C V_{\frac{n}{L}}\right)^{2}}+\left(C V_{p(x)}\right)^{2}+\left(C V_{\text {speed }}\right)^{2}+\left(C V_{\text {cluster }}\right)^{2}+\left(C V_{\text {MLE }}\right)^{2}
$$

where $C V_{\hat{N}_{p o p}}$ is the coefficient of variation of the final abundance estimate, $C V_{n}$ is the coefficient of variation of encounter rate, $C V_{p(x)}$ is the coefficient of variation of detection probabilities (adjusted for availability), $C V_{\text {speed }}$ is the coefficient of variation of swimming speeds, $C V_{\text {cluster }}^{\text {speed }}$ is the coefficient of variation of pod size, and $C V_{M L E}$ is the coefficient of variation of the migration models.

\section{Population abundance trend estimation}

For trend estimation, annual abundance estimates from NWC and from Shark Bay (from Bannister and Hedley, 2001; Hedley et al., 2011; Paxton et al., 2011) were integrated into a single data set and fitted with linear and exponential models. Model selection was based on the largest $r^{2}$. Since there were two estimates for 2008 (one from Shark Bay and one from NWC), models were fit to a data set containing the Shark Bay 2008 estimate, and then to a data set containing the NWC 2008 estimate. Trend detection reliability was then tested using TRENDS (Gerrodette, 1993).

\section{RESULTS AND DISCUSSION}

In this section, the models are first evaluated and the 'best models' selected based on the credibility of their assumptions and model fit (discussed below). Following model selection, the details of the models considered as the 'best models' are then presented in the same order as in the methods, thereby eliminating the lengthy presentation of parameter estimates from improbable models.

\section{Model selection}

A total of 3,127 whale detections were made during 74 surveys conducted over the five years (Table 1). The number of whale detections varied substantially amongst survey days (Table 1), which resulted in highly variable daily abundance estimates. As a consequence of the high variability, the migration models also varied widely in how well they fit the daily estimates.

The three migration model functions (i.e. the normal, and the mixtures of 2 and 3 normals) delivered similar results in most cases, at least when all could be plotted (e.g. there were too few surveys to fit mixture models of 2 and 3 normals for some years and migration directions, as this would have resulted in over-parameterising the model; Table 2). Overall, the mixed migration models (of 2 and 3 normals), yielded the best fit according to the corresponding AIC scores (Table 2). There was no consistency in the shape of the mixed model curves among years, however, which begged the question of whether a model with multiple modes in the migration was realistic. Furthermore, in evaluating the credibility of selecting mixed models over unimodal models for the migration of whales in any one direction, no strong support in the literature was available. Rather, there was more support for the selection of a unimodal model from a landbased study (with a relatively high sampling effort) conducted on migrating humpback whales at a similar latitude on the east coast of Australia (Noad et al., 2005). In this study, the migration followed an overall unimodal shape with variability in daily counts occurring across the entire migratory season (Noad et al., 2005). In the absence of strong evidence for a multimodel migration and given the high variability expected among daily counts, mixed models (i.e. multi-modal models) were assumed to be overfitting the underlying data rather than representing the true shape of the migration. Hence, for any single migration direction, unimodal models (i.e. single normal models) were considered to be more suited for capturing the change in densities of humpback whales over their migration past NWC.

With regard to models fitted to the entire northern and southern migratory cycle, a bimodal fit could potentially be a true reflection of the shape of the migration cycle (in which the first mode represents the northbound migration, and the second mode represents the southbound migration; as in Noad et al., 2005). If there is no lag in the crossover period between north and southbound whales at NWC however, then the true shape of the migratory cycle could arguably be unimodal. As a result of a lack of strong evidence for either case, here the 'best' models are considered to be those with the best fit (lowest AIC), regardless of whether they are unimodal or multimodal.

In comparing the results from the three approaches taken, approaches (1), (2) and (3) gave widely conflicting estimates, particularly during the last three survey years (Table 2). Similarly, models resulting from data collected during either migration direction (northern and southern) also produced different values, especially during the last three field seasons (Table 2). For example, models based on the northern migration component of approach (1) (un-truncated dataset) returned larger population estimates than their equivalents under approach (2) (truncated data set). There are several potentially contributing factors to this discrepancy. The first, and possibly most likely cause, is the inclusion of surveys conducted during the period considered to be the main southbound migration for the northern migration estimates, where southbound milling whales if temporarily travelling north, might have been erroneously classified as northbound whales. During the southbound migration, the proportion of milling animals is by far greater than during the northbound migration (Salgado Kent et al., 2010). The increased milling behaviour during the southbound migration may be 
Table 2

Estimated population size and 95\% confidence intervals (CI) based on migration models with a single normal, 2-normals, and 3-normals fit to each aerial survey year, and for: (a) a migratory direction filter applied; (b) a migratory filter and truncation at the expected end of the northern and beginning of the southern migration applied; and (c) the entire migratory cycle (no filter applied).

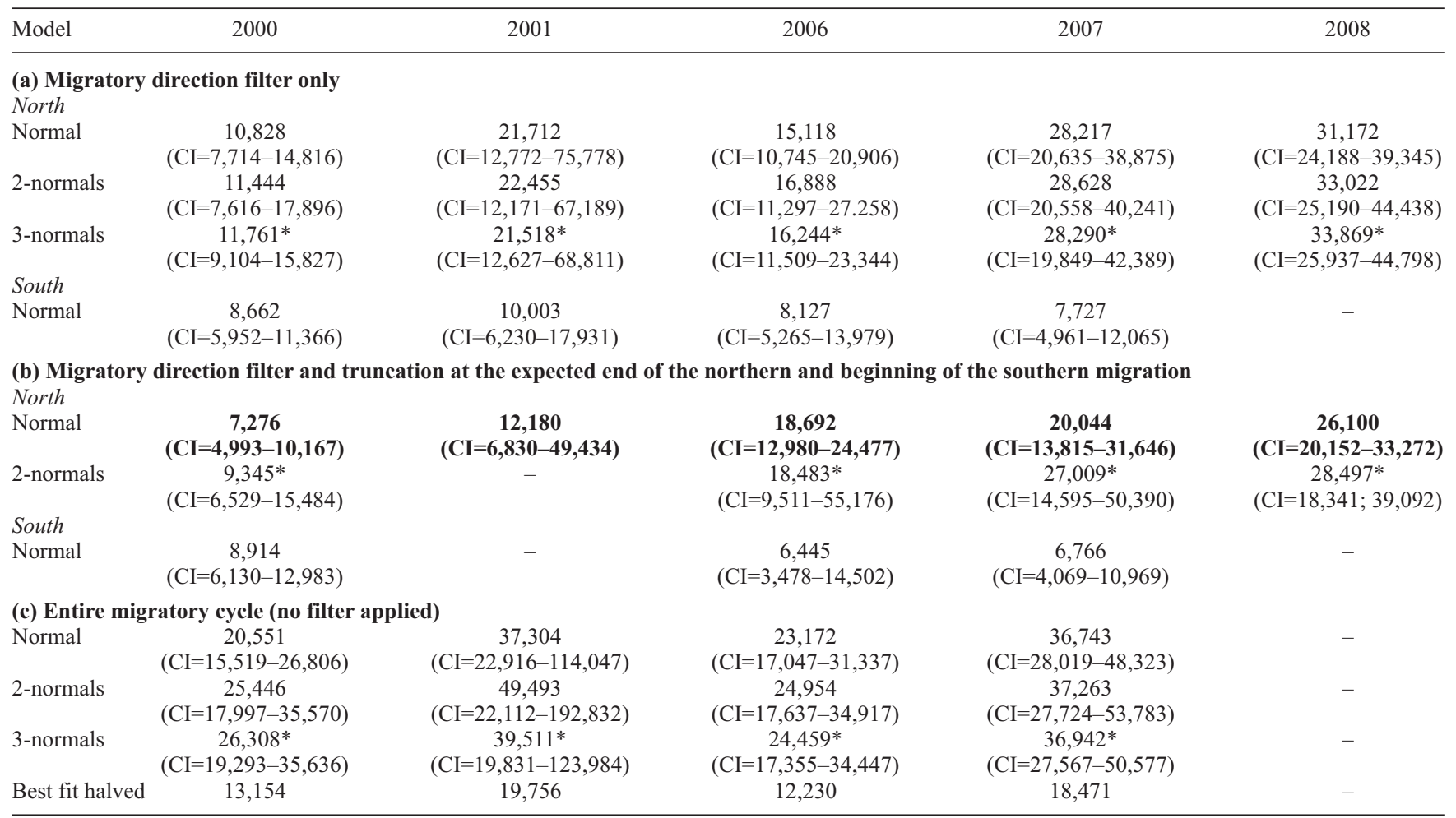

Key: *Best fit model. Bold indicates estimates used in the estimation of the trend in abundance.

associated with the use of Exmouth Gulf, just east of NWC, as a resting area for whales migrating south (Jenner et al., 2001). It is quite possible that the area west of NWC, where surveys for this study were conducted, may be an extension of this resting area or used as a transitional area between resting and migrating. The consistently small abundance estimates throughout the southbound migration in comparison to the northern migratory estimates (when Exmouth Gulf is not used by whales and there is less milling), and the sudden rise in numbers of northbound whales at the very end of the northern migration and at the beginning or middle of the southern migration (Fig. 4) are further indicators that there is an erroneous classification of northbound whales. Another factor that may have contributed to the discrepancy between the northern and southern migration estimates is that a greater number of whales, particularly cow-calf pairs as a means of protection from predators, migrate close to surf break along Ningaloo Reef during their migration south. Whales surfacing near the surf break may be more difficult to detect. A third factor that may have contributed in the discrepancy between the northern and southern migration population estimates, is the inconsistent number of surveys conducted during the two migration periods. This is particularly true during later years of the study (2006, 2007 and 2008) when the discrepancy is more pronounced. In years with the lowest estimates (2006 and 2007) field work ended in mid October, whereas 2000 and 2001 field work ended in mid November. All factors identified here as potential contributors to the inconsistencies observed in northern and southern migration estimates are artifacts that have arisen during the data collection phase.
While it is not possible to correct field-based artifacts post hoc by, for example, adding further surveys or correcting miss-recorded migration directions, placing constraints to exclude data prone to high error rates can return more reliable model based estimates.

As a result of the discrepancies from likely erroneously classified northbound whales at the end of the northern migration, the limited surveys conducted during the southern migration, and the possible lower detectability of southbound whales migrating near the surf break of Ningaloo reef, the models selected as representing the best and most credible estimates for this study were considered to be those based on the northern migration truncated at the expected end of the migration period, as per approach (2), and fitted with a single normal migration model.

\section{Abundance estimates}

For the models selected, bootstrap estimates of availability at $0.75 \mathrm{~km}$ distance (the point considered to be the best estimate of $\hat{g}(0)$ varied among years, and resulted in values of $0.58(\mathrm{SE}=0.04)$ in $2000,0.58(\mathrm{SE}=0.04)$ in $2001,0.40$ $(\mathrm{SE}=0.03)$ in $2006,0.42(\mathrm{SE}=0.03)$ in 2007 , and $0.64(\mathrm{SE}$ $=0.03)$ in 2008 .

The resulting integral of the product of the probabilities of detection and availability were similar among surveys (Fig. 5). The half normal detection function increases with perpendicular distance because the rate at which availability increased with distance outpaced the decrease in detectability given availability. This peaked at $1 \mathrm{~km}$ perpendicular distance for all years and migratory directions, and then diminished.

The mean pod size ranged from 1.21 to 1.62 (Table 3 ). 

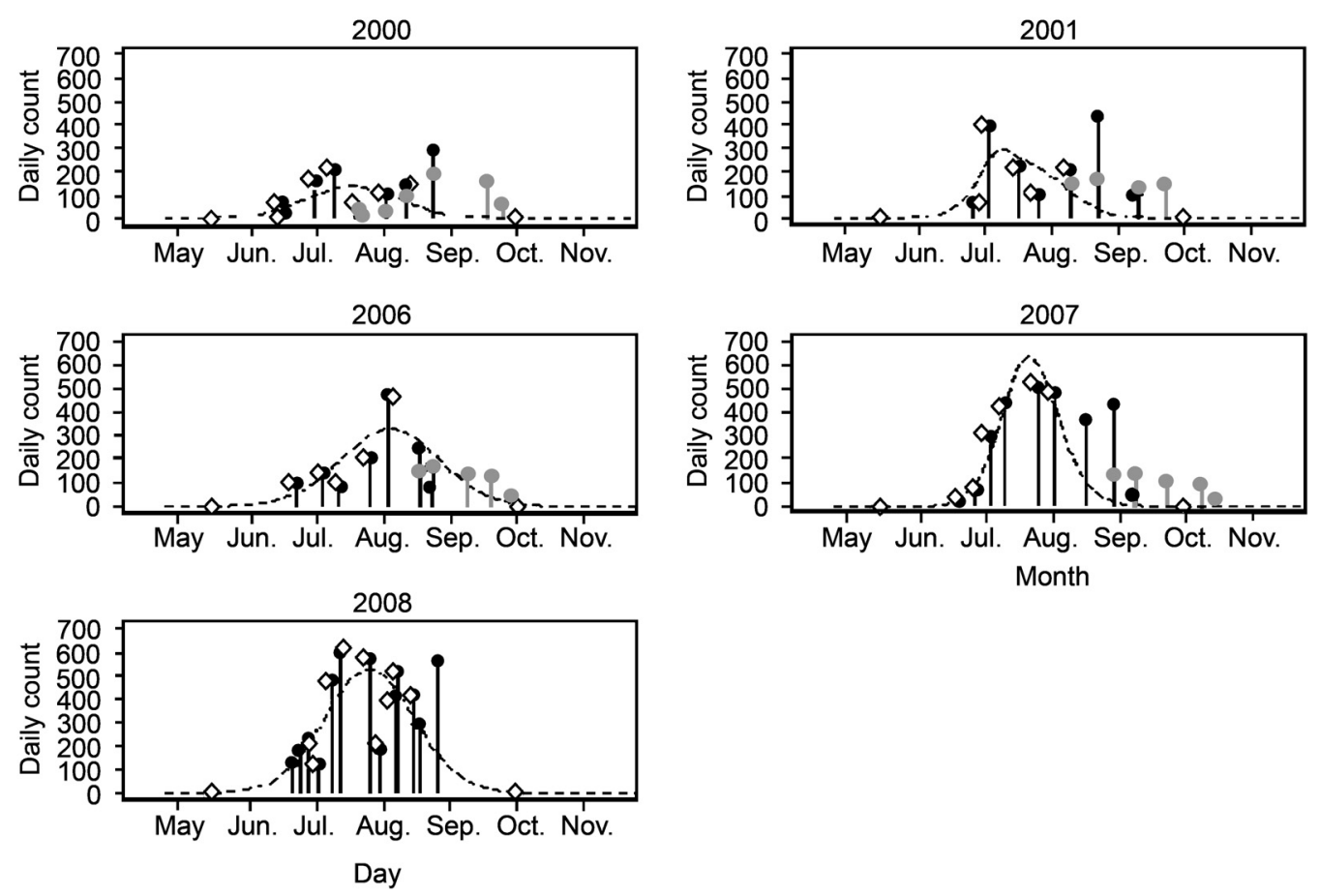

Fig. 4. Abundance estimates for the northern and southern migration using Approach no. 1 (black and grey circles, respectively), and abundance estimates and fitted migration curves (single normal) for the northern migration using Approach no. 2 (open diamonds) during 2000, 2001, 2006, 2007, and 2008. The southern migration was not surveyed in 2008 , so does not appear on the corresponding plot.

Although in most cases there were no significant differences between measured pod sizes and expected pod sizes (Table 3 ) based on regression, corrections were applied. Since there were a few cases where there were significant differences and because adjusted pod sizes in all cases but one had slightly wider confidence intervals than the unadjusted pod sizes, we chose to adjust pod size to increase accuracy and to be conservative in our assessment of uncertainty.

\section{Annual population abundance estimates using the migration models}

The single normal migration models based on the truncated northern migration and model parameters listed above resulted in the following population estimates: 7,276 (CI = 4,993-10,167) for 2000, 12,280 (CI = 6,830-49,434) for $2001,18,692(\mathrm{CI}=12,980-24,477)$ for $2006,20,044(\mathrm{CI}=$ 13,815-31,646) for 2007 and 26,100 (CI = 20,152-33,272) for 2008. These estimates were not corrected for perception bias. Based on a preliminary assessment of perception bias for the 2008 surveys which yielded a $p(0)$ of $0.783(\mathrm{CV}=$ 0.973 ), the 2008 humpback population size could be crudely estimated to be as large as 33,333. If estimates in 2000, 2001, 2006 and 2007 accounted for perception bias, they could also be expected to be greater than the values reported above (e.g. crude predictions based on the 2008 perception bias estimates result in 9,292 for 2000, 15,683 for 2001, 23,872 for 2006, and 25,598 for 2007). The large CV associated with perception bias, however, suggests that future work should aim at reducing the uncertainty of its estimation.

\section{Population abundance trend estimation and comparison to Shark Bay population estimates}

The function for trend estimation (for population estimates uncorrected for perception bias) for the NWC data with the highest $r^{2}(0.92)$ was exponential with an increase rate of $13 \% \mathrm{yr}^{-1}\left(\mathrm{SE}=2.3 \%\right.$, Equation: $\left.x(\mathrm{t})=x_{0} e^{0.1314 t}\right)$. While this increase rate is probably not biologically possible (Zerbini et al., 2010), it is only just above previous estimates of between $10-12 \% \mathrm{yr}^{-1}$ and has a high associated standard error. For the NWC and Shark Bay data combined, the highest $r^{2}(0.78)$ was an exponential fit of $11.9(\mathrm{SE}=2.6 \%$, Equation: $\left.x(\mathrm{t})=x_{0} e^{0.1186 t}\right)$ which is at the upper limit of what is considered to be biologically possible. Based on a power analysis (using TRENDS and setting $\alpha=0.05$ and power, $1-\beta,=0.8) 5$ more consecutive survey years would be required to reliably detect a $10 \% \mathrm{yr}^{-1}$ change, and 9 to reliably detect a $5 \% \mathrm{yr}^{-1}$ change. If survey years were staggered, then 3 over 6 years, and 7 over 13 years would be required for the same levels of detectable change (respectively).

In comparing NWC estimates to those from approximately $400 \mathrm{~km}$ south at Shark Bay (Bannister and Hedley, 2001; Hedley et al., 2011; Paxton et al., 2011) modelling approaches varied greatly, however, no major anomalies (data points that would appear to be outliers) were detected in an integrated NWC and Shark Bay trend estimate, except for a difference in population estimates in 2008 (33,850 for Shark Bay and 26,100 for NWC). It is worth noting that the crude NWC estimate $(33,333)$ which accounts for perception bias is much more similar to the 2008 Shark Bay estimate of approximately 34,000 (which also accounts for perception bias). An exponential function was again associated with the lowest $r^{2}$ for the combined NWC and Shark Bay trend estimate. The exponential increase rate was $12.3 \% \mathrm{yr}^{-1}$, which is a value closer to the calculated maximum plausible increase rate (Zerbini et al., 2010). While the increase rate estimate is similar to previous estimates, the large coefficient of variation associated with the estimates, again, is too large 


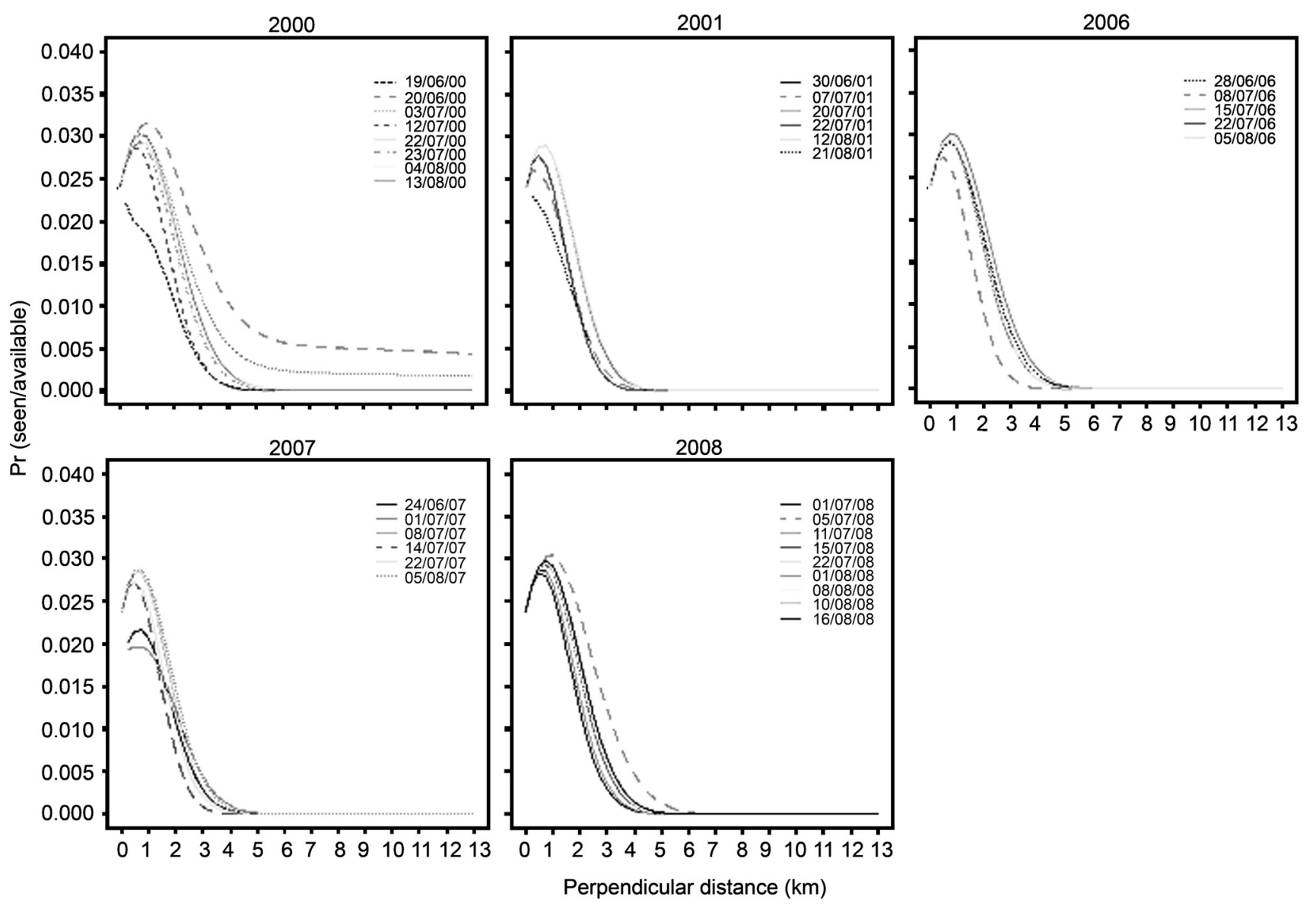

Fig. 5. Probability of detection of a humpback pod given perpendicular distance from flight line (adjusted for availability) for the northern migration. Lines represent separate detection function fitted to each survey, using a $13 \mathrm{~km}$ right truncation distance.

to conclusively determine the population growth rate (Fig. 6). The work here, however, can be said to confidently provide evidence of an increasing Breeding Stock D humpback whale population, and brings us closer to reliable trend detection.

\section{Uncertainty}

Overall, the greatest source of variation was found to reside in the MLE migration models themselves (Table 4; and most notable for the 2001 data). This uncertainty stems from the limited number of samples (aerial surveys) at hand, but may also be influenced by the probable field based errors made in identifying whales' travel directions. Adjusted detection probabilities also constituted a significant source of variability, which was most likely a function of the accuracy in $\hat{g}(0)$ estimates. To address these limitations and improve future estimates, double platform surveys (preferably aerial and land-based platforms) with a major overlap in whales sampled is recommended if possible, and either land or aerial survey sample size increased. Land based surveys would provide a non-instantaneous record of migration direction (as opposed to aerial surveys), and would provide an alternative and potentially more accurate method for estimating $\hat{g}(0)$. Depending upon the practicality of landbased surveys, however, alternative methods such as using a vessel as an alternative platform or tagging whales with packages that provide information on whale movement and surfacing patterns, may help reduce some of the sources of uncertainty and increase the accuracy of the models.

\section{ACKNOWLEDGEMENTS}

The field work for this project was made possible by funding provided to the Centre for Whale Research by BHP Billiton Petroleum and Woodside Energy. The Australian Marine Mammal Centre provided funding for analysis and synthesis (AMMC grant no. 0809/9). Also, valuable guidance was provided by David Borchers from the Centre for Research into Environmental and Ecological Management at the University of St. Andrews, from Alec Duncan and Robert McCauley at the Centre for Marine Science and Technology at Curtin University, and from Sonja Heinrich from the Sea Mammal Research Unit at the University of St. Andrews. These contributions, in addition to the suggestions of two anonymous reviewers, significantly improved the quality of the results of this study.

A large number of individuals were involved in data collection and formatting, including Lyn Irvine, Vanessa Boladeras, Jane Kennedy, Emily Wilson, Jennifer

\section{Table 3}

Mean pod size and adjusted mean pod size $( \pm$ SE) for used for estimating abundance from surveys conducted in 2000, 2001, 2006, 2007, 2008.

\begin{tabular}{ccc}
\hline Year & Mean pod size & Adj. mean pod size \\
\hline 2000 & $1.21 \pm 0.04$ & $1.26 \pm 0.05$ \\
2001 & $1.52 \pm 0.13$ & $1.54 \pm 0.14$ \\
2006 & $1.43 \pm 0.05$ & $1.56 \pm 0.04$ \\
2007 & $1.62 \pm 0.04$ & $1.77 \pm 0.04$ \\
2008 & $1.42 \pm 0.02$ & $1.60 \pm 0.03$ \\
\hline
\end{tabular}




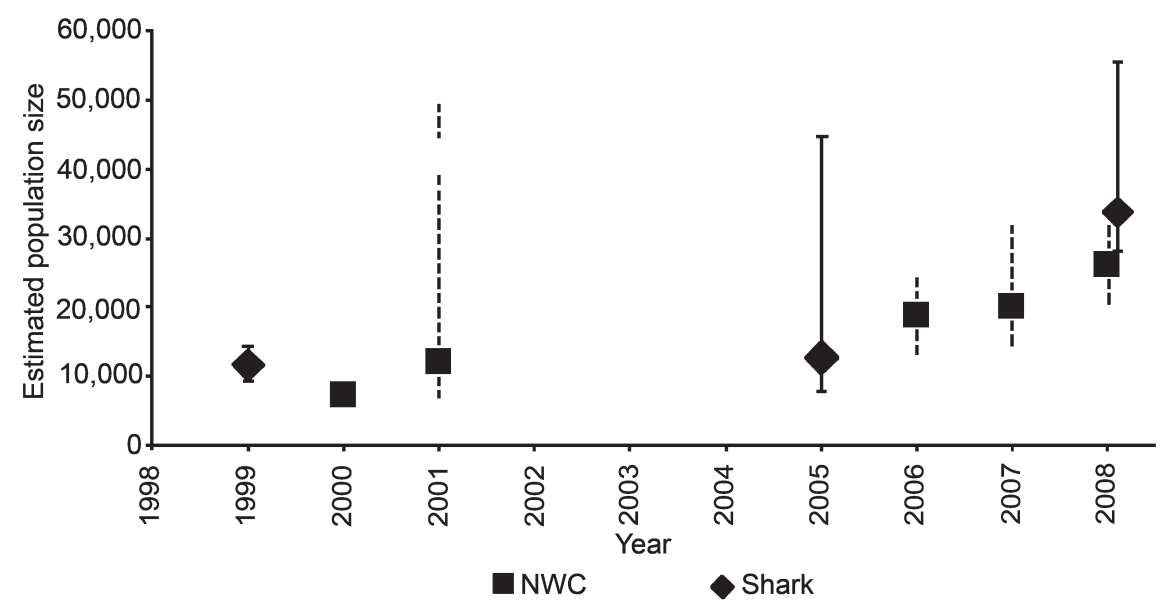

Fig. 6. Trend in population size based on the best available estimates from North West Cape and Shark Bay, Western Australia.

Table 4

Coefficients of variation for all parameters used for estimating the population size from surveys conducted in 2000, 2001, 2006, $2007,2008$.

\begin{tabular}{|c|c|c|c|c|c|}
\hline Source of variation & 2000 & 2001 & 2006 & 2007 & 2008 \\
\hline Coefficient of variation of encounter rate $\left(C V \frac{N}{L}\right)$ & 0.127 & 0.131 & 0.130 & 0.123 & 0.066 \\
\hline Coefficient of variation of detectabilites (adjusted for availability) $\left(C V_{p(x)}\right)$ & 0.238 & 0.107 & 0.091 & 0.102 & 0.077 \\
\hline Coefficient of variation of swimming speeds $\left(C V_{\text {speed }}\right)$ & 0.058 & 0.057 & 0.056 & 0.061 & 0.059 \\
\hline Coefficient of variation of pod size $\left(C V_{\text {cluster }}\right)$ & 0.070 & 0.207 & 0.047 & 0.050 & 0.031 \\
\hline Coefficient of variation of the migration models $\left(C V_{M L E}\right)$ & 0.181 & 0.939 & 0.17 & 0.185 & 0.123 \\
\hline Coefficient of variation of the final abundance estimate $\left(C V_{\hat{N}_{\text {pop }}}\right)$ & 0.34 & 0.97 & 0.24 & 0.26 & 0.17 \\
\hline
\end{tabular}

Thompson, Caroline Williams, Tim Williams, Sharon McKinna-Jones, Shannon McKay, Lucie Grignon, Susie Bedford and Kerstin Bilgmann.

\section{REFERENCES}

Bannister, J.L. 1964. Australian whaling 1963. Catch results and research Aust. CSIRO Div. Fish. Oceanogr. Rep. 38: 1-13, plus 7 tables and 4 figs.

Bannister, J.L. 1991. Western Australian humpbacks since 1963. Mem. Queensl. Mus. 30(2): 258.

Bannister, J.L. 1994. Continued increase in humpback whales off Western Australia. Rep. int. Whal. Commn 44: 309-10.

Bannister, J.L. and Hedley, S.L. 2001. Southern Hemisphere group IV humpback whales: their status from recent aerial survey. Mem. Queensl. Mus. 47(2): 587-98.

Bannister, J.L., Kirkwood, G.P. and Wayte, S.E. 1991. Increase in humpback whales off western Australia. Rep. int. Whal. Commn 41: 461-65.

Borchers, D.L., Buckland, S.T. and Zucchini, W. 2002. Estimating Animal Abundance: closed populations. Statistics for Biology and Health Series, Spring-Verlag, London. i-xii $+314 \mathrm{pp}$.

Bouchet, P. 2009. Don't count your whales before they migrate: using aerial surveys to assess the status of stock D humpbacks (Megaptera novaeangliae) in Western Australia. MSc thesis, University of St Andrews, St Andrews.

Buckland, S.T., Anderson, D.R., Burnham, K.P., Laake, J.L., Borchers, D.L. and Thomas, L. 2001. Introduction to Distance Sampling: Estimating Abundance of Biological Populations. Oxford University Press, Oxford, UK. vi $+\mathrm{xv}+432 \mathrm{pp}$.

Buckland, S.T., Anderson, D.R., Burnham, K.P., Laake, J.L., Borchers, D.L. and Thomas, L. 2004. Advanced Distance Sampling: Estimating Abundance of Biological Populations. Oxford University Press, Oxford, UK. 416pp.

Chittleborough, R.G. 1953. Aerial observations on the humpback whale (Megaptera novaeangliae) (Borowski), with notes on other species. Aust. J. Mar. Freshwater Res. 4(2): 219-26.

Chittleborough, R.G. 1965. Dynamics of two populations of the humpback whale, Megaptera novaeangliae (Borowski). Aust. J. Mar. Freshwater Res. 16(1): 33-128.

Gerrodette, T. 1993. TRENDS: Software for a power analysis of linear regression. Wildl. Soc. Bull. 21: 515-16.

Hedley, S.L., Bannister, J.L. and Dunlop, R.A. 2011. Abundance estimates of Breeding Stock 'D' humpback whales from aerial and land-based surveys off Shark Bay, Western Australia, 2008. J. Cetacean Res. Manage (special issue 3): 209-21.

International Whaling Commission. 1998. Report of the Scientific Committee. Annex G. Report of the sub-committee on Comprehensive Assessment of Southern Hemisphere humpback whales. Appendix 4. Initial alternative hypotheses for the distribution of humpback breeding stocks on the feeding grounds. Rep. int. Whal. Commn 48:181.

Jenner, K.C.S., Jenner, M.N.M. and McCabe, K.A. 2001. Geographical and temporal movements of humpback whales in Western Australian waters. APPEA Journal 2001: 749-65.

Laake, J.L., Calambokidis, J., Osmek, S.D. and Rugh, D.J. 1997. Probability of detecting harbour porpoise from aerial surveys: Estimating $g(0) . J$. Wildl. Manage. 61(1): 63-75.

Lerczak, J.A. and Hobbs, R.C. 1998. Calculating sighting distances from angular readings during shipboard, aerial, and shore-based marine mammal surveys. Mar. Mammal Sci. 14(3): 590-99. [See Errata. 1998. Mar. Mammal Sci. 14(4):903].

Noad, M.J., Cato, D.H. and Paton, D. 2005. Absolute and relative abundance estimates of Australian east coast humpback whales (Megaptera novaeangliae). Paper SC/57/SH12 presented to the IWC Scientific Committee, June 2005, Ulsan, Korea (unpublished). 9pp. [Paper available from the Office of this Journal].

Paxton, C.G.M., Hedley, S.L. and Bannister, J.L. 2011. Group IV humpback whales: their status from aerial and land-based surveys off Western Australia, 2005. J. Cetacean Res. Manage. (special issue 3): 223-34.

Salgado Kent, C., Jenner, C. and Jenner, M. 2010. Are sex biases associated with boat-based biopsy sampling of humpback whales a true reflection of sex-ratio? A study based on southern hemisphere breeding stock D humpback whales at North West Cape, Western Australia. CMST Report no. 2010-16. Prepared for the AMMC.

Thomas, L., Buckland, S.T., Rexstad, E.A., Laake, J.L., Strindberg, S., Hedley, S.L., Bishop, J.R.B., Marques, T.A. and Burnham, K.P. 2010. Distance software design and analysis of distance sampling surveys for estimating population size. J. Appl. Ecol. 47: 5-14.

Zerbini, A.N., Clapham, P.J. and Wade, P.R. 2010. Assessing plausible rates of population growth in humpback whales from life-history data. Mar. Biol. 157(6): 1225-36.

Date received: July 2010

Date accepted: March 2011 